\title{
MEMPERKENALKAN MANAJEMEN PRODUKSI DAN SUMBER DAYA MANUSIA YANG BAIK PADA PETANI DALAM MEMPRODUKSI APEL MENJADI PRODUKSI MANISAN PADA PETANI APEL DI DESA SUMBERGEDE, BUMIAJI
}

\author{
Angga Pratama, Lismiatun, Eka Rahim, Khoirunisa , Frans Bonar Sihite
}

Dosen Ekonomi Fakultas Ekonomi Universitas Pamulang

\begin{abstract}
Email : dosen02155@unpam.ac.id, dosen01460@unpam.ac.id, dosen00743@unpam.ac.id dosen01736@unpam.ac.id,
\end{abstract}

\begin{abstract}
ABSTRAK
Pengabdian ini berjudul Memperkenalkan Manajemen Produksi dan Sumber Daya Manusia yang Baik Pada Petani dalam Memproduksi Apel Menjadi Produksi Manisan Pada Petani Apel di Desa Sumbergede, Bumiaji.

Tujuan pengabdian ini adalah untuk memberika pelatihan pengolahann buah apel menjadi produksi manisan pada petani apel, memberikan keterampilan dalam mempromosikan hasil produksi manisan apel dari desa sumbergede, bumiaji dan menganalisa penetapan harga serta menganalisa lingkungan dari hasil produksi manisan apel. Metode pelaksanaan pengabdian ini dilakukan dalam beberapa kegiatan yaitu tahap persiapan yaitu dengan survei yang dilakukan dengan menyusun berbagai hal yang akan disampaikan pada saat kegiatan pengabdian yang akan dilakukan yang meliputi: penyusunan materi yang akan diberikan, penyusunan jadwal pemberian materi, pembagian tugas tim pengabdian dan survei ke lokasi pengabdian. Tahap pelaksanaan pelatihan dilakukan dengan memberi penjelasan tentang bagaimana memotivasi para petani untuk meningkatkan penghasilannya, sesi ini menitikberatkan pada pemberian motivasi dan contohcontoh yang sudah bisa diterapkan dalam meningkatkan penghasilan dan membangun jiwa yang optimis. Selain itu juga terdapat metode simulasi yang diberikan kepada peserta pelatihan dalam rangka mempraktekkan materi yang diperoleh. Tim pengabdian memberikan materi tentang Manajemen Produksi dan Sumber Daya Manusia yang Baik Pada Petani dalam Memproduksi Apel Menjadi Produksi Manisan Pada Petani Apel di Desa Sumbergede, Bumiaji

Kesimpulan dari pengabdian ini adalah masih banyak peserta yang kurang mengerti bagaimana Manajemen Produksi dan Sumber Daya Manusia yang Baik dalam Memproduksi Apel Menjadi Produksi Manisan. Harapan kami dengan pengabdian ini dapat membuka wawasan petani mengenai Manajemen Produksi dan Sumber Daya Manusia yang baik sehingga akan menambah keilmuan bagi para petani, khususnya pada petani apel di Desa Sumbergede, Bumiaji. Pada Pengabdian Masyarakat kali ini diharapkan mampu memberikan semangat baru bagi kita dalam menyampaikan materi dan motivasi serta berkontribusi bagi generasi muda, baik dilingkungan sekolah, kampus dan keluarga.
\end{abstract}

\section{Kata Kunci: Manajemen Produksi, Sumber Daya Manusia}

\section{ABSTRACT}

This service is entitled Introducing Good Management of Production and Human Resources in Farmers in Producing Apples into Candied Production in Apples Farmers in Sumbergede Village, Bumiaji. 
The purpose of this service is to provide training on the processing of apples into candied production to apple farmers, providing skills in promoting the production of candied apples from Sumbergede villages, bumiaji and analyzing pricing and analyzing the environment of apple candied production. The method of implementing this service is carried out in a number of activities, namely the preparation stage, namely by conducting a survey by compiling various things that will be delivered at the time of service activities that will be carried out which include: preparation of material to be given, preparation of material delivery schedule, division of tasks of the service team and survey to the location of service. The training phase is carried out by giving an explanation of how to motivate farmers to increase their income, this session focuses on providing motivation and examples that can be applied in increasing income and building an optimistic spirit. In addition there are also simulation methods given to training participants in order to practice the material obtained. The dedication team provided material on Good Production and Human Resources Management to Farmers in Producing Apples into Candied Production in Apples Farmers in Sumbergede Village, Bumiaji

The conclusion from this dedication is that there are still many participants who do not understand how Production Management and Good Human Resources in Producing Apples Into Candied Production. Our hope is that this dedication can open up farmers' insights on good Production and Human Resources Management so that they will increase knowledge for farmers, especially for apple farmers in Sumbergede Village, Bumiaji. At this time Community Service is expected to be able to provide new enthusiasm for us in conveying material and motivation as well as contributing to the young generation, both within the school, campus and family environment

\section{Keywords: Production Management, Human Resources}

\section{PENDAHULUAN}

Indonesia sebagai negara agraris yang memiliki kekayaan alam dan hayati yang sangat beragam jika dikelola dengan tepat. Kekayaan tersebut mampu diandalkan menjadi andalan perekonomian nasional. Kondisi ini sangat sesuai untuk pengembangan komoditas tropis dan sebagian sub tropis pada ketinggian antara nol sampai ribuan meter di atas permukaan laut. Komoditas pertanian (mencakup tanaman pangan, hortikultura, perkebunan, kehutanan, peternakan dan lain-lain) dengan keragaman dan keunikannya yang bernilai tinggi serta diperkuat oleh kekayaan kultural yang sangat beragam mempunyai daya Tarik kuat sebagai Wisata Agroindustri. Keseluruhannya sangat berpeluang besar menjadi andalan dalam perekonomian Indonesia yang berkaitan dengan manajemen agribisnis.

Agribisnis berasal dari Agribusiness, dimana Agri adalah Agriculture artinya pertanian dan Business artinya usaha atau kegiatan yang berorientasi profit. Jadi, secara sederhana agribisnis dapat didefinisikan sebagai usaha atau kegiatan pertanian dan terkait dengan pertanian yang berorientasi profit. Agribisnis merupakan bisnis berbasis usaha pertanian atau bidang lain yang mendukungnya, baik di sektor hulu maupun di sektor hilir. Agribisnis merupakan suatu sistem kompleks yang saling berhubungan yang terdiri dari beberapa subsistem yaitu: pengadaan dan penyaluran sarana produksi (input), proses produksi primer (farm), pengolahan dan pemasaran.

Subsistem pengolahan disebut juga agroindustri yang terdiri dari agroindustri hulu yaitu penghasil input pertanian dan agroindustri hilir yaitu industri pengolahan hasil pertanian primer dan bahkan lebih luas lagi mencakup industry sekunder dan tersier yang mengolah lebih lanjut dari produk olahan hasil pertanian primer. Salah satu contoh agroindustri hilir adalah 
Program Studi Ekonomi Manajemen Universitas

Jurnal LOKABMAS Kreatif Vol. 01, No. 01, Hal. 83-88

Email:jurnalkreatif.manajemen@gmail.com

usaha pengolahan manisan apel. Seiring dengan perkembangan teknologi, saat ini banyak bermunculan inovasi pengolahan apel. Salah satunya adalah manisan apel. Prospek usaha manisan apel ini cukup menjanjikan karena hanya membutuhkan modal yang relatif sedikit namun keuntungannya relatif besar.

Pengembangan desa wisata agro adalah merupakan hal yang sangat penting terutama bagi daerah yang memilliki potensi wisata agro, seperti Kota Batu, Jawa Timur. Sebagaimana Visi Kota Batu: "Kota Batu Sentra Pertanian Organik Berbasis Kepariwisataan Internasional". Wilayah yang dikembangkan sebagai Kawasan wisata agro berdasarkan pada luas wilayah kecamatan Bumiaji sebesar $12.798,42$ Ha atau $64 \%$ dari total luas Kota Batu yaitu 19.908,73 Ha. Dalam pelaksanaanya pengembangan kawasan wisata agro di kecamatan Bumiaji Kota Batu belum dapat berjalan secara maksimal. Pengabdian ini sesuai dengan program pengembangan sektor pariwisata di Kota Batu.

\section{RUMUSAN MASALAH}

Dengan mempertimbangkan latar belakang yang telah diutarakan diatas kami berinisiatif untuk membentuk pengabdian masyarakat bagi petani apel melalui progam penyuluhan materi mengenai Manajemen Produksi dan Sumber Daya Manusia yang Baik dalam Memproduksi Apel Menjadi Produksi Manisan oleh dosen UNPAM di Desa Sumbergede, Bumiaji

\section{TUJUAN PELAKSANAAN}

1. Memberikan pelatihan pengolahan buah apel menjadi produksi manisan pada petani apel.

2. Memberikan keterampilan dalam mempromosikan hasil produksi manisan apel di desa Sumbergede, Bumiaji.
3. Menganalisa penetapan harga dan menganalisa lingkungan dari hasil produksi manisan apel.

\section{TINJAUAN PUSTAKA}

\section{Pengertian Agribisnis}

Agribisnis adalah semua aktivitas dalam bidang pertanian. Mulai dari industri hulu, usaha tani, indutri hilir hingga distribusinya. (Soekartawi, 1993) Agribisnis dapat bergerak dalam berbagai macam kegiatan, kaitannya dengan sektor hulu, usahatani, maupun hilir. Agribisnis juga dapat dilakukan dari tingkat skala kecil (usahatani) sampai dengan skala besar (perusahaan agribisnis), yang dapat dilakukan oleh seseorang atau sekelompok orang.

\section{Pengertian Manajemen}

Pengertian manajemen secara umum dapat disimpulkan dari beberapa definisi menurut para ahli. Hal ini karena ada banyak versi definisi manajemen. Misalnya saja manajemen menurut seorang ahli bernama Mary Parker Follet yang mendefinisikan manajemen sebagai seni merampungkan pekerjaan melalui orang lain. Dari definisi tersebut didapati bahwa seseorang yang bertugas sebagai manajer dapat mengarahkan dan mengatur orang lain guna mencapai tujuan organisasi.

Di sisi lain, James A.F Stoner mendefinisikan manajemen sebagai proses pengorganisasian, perencanaan, dan penggunaan SDM supaya mencapai tujuan organisasi yang sudah ditetapkan.

Secara umum, pengertian manajemen merupakan suatu seni dalam ilmu dan pengorganisasian seperti menyusun perencanaan, membangun organisasi dan pengorganisasiannya, pergerakan, serta pengendalian atau pengawasan. Bisa juga diartikan bahwa manajemen merupakan suatu ilmu pengetahuan yang sistematis agar dapat memahami mengapa dan bagaimana manusia saling bekerja sama agar dapat menghasilkan sesuatu yang 
bermanfaat bagi orang lain maupun golongan tertentu dan masyarakat luas.

Secara etimologis, pengertian manajemen merupakan seni untuk melaksanakan dan mengatur. Manajemen ini juga dilihat sebagai ilmu yang mengajarkan proses mendapatkan tujuan dalam organisasi, sebagai usaha bersama dengan beberapa orang dalam organisasi tersebut. Sehingga, ada orang yang merumuskan dan melaksanakan tindakan manajemen yang disebut dengan manajer.

\section{Fungsi Manajemen}

Pada dasarnya, fungsi manajemen dibagi menjadi tiga, yaitu:

\section{a. Perencanaan (planning)}

Pernecanaan adalah memikirkan apa yang akan dikerjakan dengan sumber yang dimiliki. Perencanaan dilakukan untuk menentukan tujuan perusahaan secara keseluruhan dan cara terbaik untuk memenuhi tujuan itu. Manajer mengevaluasi berbagai rencana alternatif sebelum mengambil tindakan dan kemudian melihat apakah rencana yang dipilih cocok dan dapat digunakan untuk memenuhi tujuan perusahaan. Perencanaan merupakan proses terpenting dari semua fungsi manajemen karena tanpa perencanaan, fungsi-fungsi lainnya tak dapat berjalan.

\section{b. Pengorganisasian (organizing)}

Pengorganisasian dilakukan dengan tujuan membagi suatu kegiatan besar menjadi kegiatan-kegiatan yang lebih kecil. Pengorganisasian mempermudah manajer dalam melakukan pengawasan dan menentukan orang yang dibutuhkan untuk melaksanakan tugas-tugas yang telah dibagi-bagi tersebut. Pengorganisasian dapat dilakukan dengan cara menentukan tugas apa yang harus dikerjakan, siapa yang harus mengerjakannya, bagaimana tugas-tugas tersebut dikelompokkan, siapa yang bertanggung jawab atas tugas tersebut, dan pada tingkatan mana keputusan harus diambil.

\section{c. Pengarahan (directing)}

Pengarahan adalah suatu tindakan untuk mengusahakan agar semua anggota kelompok berusaha agar dapat mencapai sasaran sesuai dengan perencanaan manajerial dan usaha

\section{Pengertian manajemen Sumber Daya Manusia}

Manajemen sumber daya manusia merupakan bagian dari ilmu manajemen yang memfokuskan perhatianya pada pengaturan peranan sumber daya manusia dalam kegiatan organisasi. Hal ini dikarnakan dalam mencapai tujuanya, organisasi memerlukan sumber daya manusia sebagai pengeelola sistemnya, dan agar sistem ini berjalan, dalam pengelolaanya diperlukan beberapa aspek penting, seprti pelatihan, pengembangan, motivasi dan aspek-aspek lainya. Hal ini yang menjadikan manajeman sumber daya manusia sebagai salah satu indikator penting pencapaian tujuan organisasi secara efektif dan efisien. (mila badriah, S.E.,M.M, 15: 2015).

Manusia selalu berperan aktif dan dominan dalam kegiatan organisasi karena manusia menjadi perencana, pelaku, dan penentu terwujudanya tujuan organisasi. Tujuan tidak mungkin terwujud tanpa peran aktif tanpa peran karyawan meskipun alat-alat yang dimiliki oleh perusahaan begitu canggih. Alat-alat canggih perusahaan tidak ada manfaatnya bagi perusahaan, jika peran aktif karyawan tidak di ikut sertakan. Mengatur karyawan merupakan hal yang sulit dan kompleks karena mereka mempunyai pikiran, perasaan, status, keinginan, dan latar belakang yang heterogen yang dibawa kedalam suatu organisasi. Karyawan tidak dapat di atur dan dikuasai sepenuhnya seperti mengatur mesin, moda, dan gedung. 
Program Studi Ekonomi Manajemen Universitas

Jurnal LOKABMAS Kreatif Vol. 01, No. 01, Hal. 83-88

Email:jurnalkreatif.manajemen@gmail.com

Manajemen sumber daya manusia merupakan bagian dari manajemen. Oleh karna itu, teori-teori manajemen umum manjadi dasar pembahasaannya mengenai pengaturan peranaan manusia dalam menentukan tujuan yang optimal.

Pengertian manajeman sumber daya manusia menurut malyu S.P. hasibuan ( 2005: 10 ) yang menyatakan bahwa :

"manajeman sumber daya manusia adalah ilmu dan seni yang mengatur hubungan dan peranan tenaga kerja yang efektif dan efisien membantu terwujudnya tujuan perusahaan, karyawan, dan masyarakat".

\section{METODE PELAKSANAAN}

Metode pelaksanaan pengabdian ini dilakukan dalam beberapa kegiatan yaitu tahap persiapan yaitu dengan survei yang dilakukan dengan menyusun berbagai hal yang akan disampaikan pada saat kegiatan pengabdian yang akan dilakukan yang meliputi: penyusunan materi yang akan diberikan, penyusunan jadwal pemberian materi, pembagian tugas tim pengabdian dan survei ke lokasi pengabdian. Tahap pelaksanaan pelatihan dilakukan dengan memberi penjelasan tentang bagaimana memotivasi para petani untuk meningkatkan penghasilannya, sesi ini menitikberatkan pada pemberian motivasi dan contoh-contoh yang sudah bisa diterapkan dalam meningkatkan penghasilan dan membangun jiwa yang optimis. Selain itu juga terdapat metode simulasi yang diberikan kepada peserta pelatihan dalam rangka mempraktekkan materi yang diperoleh. Tim pengabdian memberikan materi tentang Manajemen Produksi dan Sumber Daya Manusia yang Baik Pada Petani dalam Memproduksi Apel Menjadi Produksi Manisan Pada Petani Apel di Desa Sumbergede, Bumiaji

\section{HASIL DAN PEMBAHASAN}

Pengabdian Masyarakat (PKM) Universitas Pamulang yang dilakukan oleh dosen-dosen program studi Manajemen telah berjalan dengan lancar dan mendapat sambutan hangat dari tempat pelaksanaan kegiatan ini yaitu di Desa Sumbergede, Bumiaji

Harapan kami dengan pengabdian ini dapat membuka wawasan petani mengenai Manajemen Produksi dan Sumber Daya Manusia yang baik sehingga akan menambah keilmuan bagi para petani, khususnya pada petani apel di Desa Sumbergede, Bumiaji. Pada Pengabdian Masyarakat kali ini diharapkan mampu memberikan semangat baru bagi kita dalam menyampaikan materi dan motivasi serta berkontribusi bagi generasi muda, baik dilingkungan sekolah, kampus dan keluarga.

\section{KESIMPULAN DAN SARAN Kesimpulan}

Masih banyak peserta yang merupakan petani apel yang kurang mengerti bagaimana Manajemen Produksi dan Sumber Daya Manusia yang Baik dalam Memproduksi Apel Menjadi Produksi Manisan.

\section{Saran}

Setelah pengabdian ini diharapkan peserta yang dalam hal ini adalah petani apel dapat memiliki pengetahuan mengenai manajemen produksi serta memiliki manajemen sumber daya manusia yang baik sehingga akan berpengaruh terhadap keuntungan atau laba dalam memproduksi manisan apel khususnya di Desa Sumbergede, Bumiaji.

\section{DAFTAR PUSTAKA}

Assauri, Sofyan.1999. Manajemen Produksi dan Operasi. Lembaga Penerbit Fakultas Ekonomi. Universitas Ekonomi. Jakarta.

David, Fred R. 2006. Manajemen Strategis: Konsep, Edisi 10. Salemba Empat. Jakarta. 
Kotler. Philip. 1997. Manajemen Pemasaran. Terjemahan. Jilid 1. Prehalindo. Jakarta.

Pasaribu, V. L. D., Agrasadya, A., Shabrina, N., \& Krisnaldy, K. (2020). MENJADI ENTERPRENEUR MUDA YANG MEMILIKI JIWA LEADERSHIP UNTUK MENGHADAPI MASA DEPAN. Abdi Laksana, 1(1)

DOKUMENTASI FOTO KEGIATAN

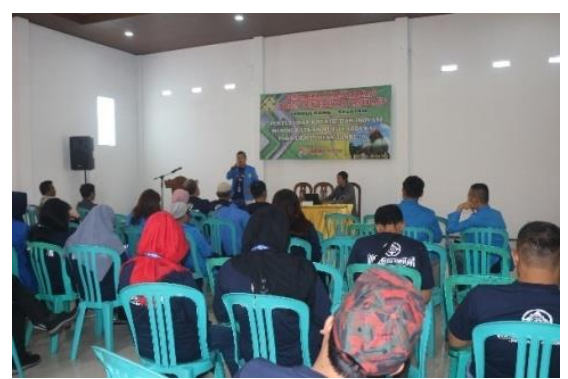

Pasaribu, V. L. D., Elburdah, R. P., Sudarso, E., \& Fauziah, G. (2020). PENGGUNAAN MANAJEMEN WAKTU TERHADAP PENINGKATAN PRESTASI BELAJAR DI SMP ARAISIYAH. Jurnal ABDIMAS, l(1)

Pasaribu, V. L. D., Susanti, F., \& Hartuti, E. T. K. (2019). MEMOTIVASI SISWA DAN SISWI SMK LETRIS INDONESIA DI DALAM MENENTUKAN PILIHAN UNTUK MELANJUTKAN PENDIDIKAN ATAU BEKERJA SETELAH LULUS SEKOLAH. Jurnal Pengabdian Dharma Laksana, 1(2), 161172.

Suliyanto. 2010. Studi Kelayakan Bisnis. Andi. Yogyakarta.

Stanton. Wiliam. J. 1984. Fundamentals of Marketing. McGraw Hill. New York.

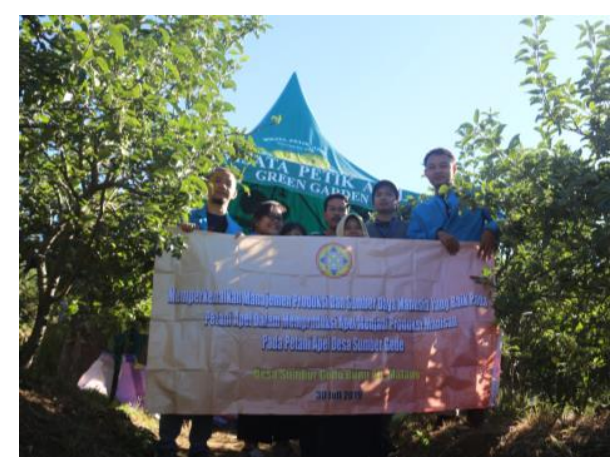

